\title{
Major risk factors for pressure ulcers in the spinal cord disabled: a literature review
}

\author{
DW Byrne and CA Salzberg \\ Division of Plastic and Reconstructive Surgery; New York Medical College, Westchester County Medical Center, \\ Valhalla, New York and The Spinal Cord Injury Unit, Castle Point Veterans Affairs Medical Center, Castle Point, \\ New York, USA.
}

\begin{abstract}
Pressure ulcers remain a dominant health problem for persons with spinal cord injury despite abundant published research describing risk factors. Although information on these factors is plentiful, its usefulness to the spinal cord disabled is limited by three problems. First, the sheer volume is overwhelming; more than 200 risk factors for pressure ulcers have been described in the published literature. For most health care professionals, finding, no less reading and evaluating, the hundreds of articles published on this topic would be difficult. Second, most studies focused on elderly patients in nursing homes. Pressure ulcer risk factors for the spinal cord disabled are often different from those for the elderly; yet many findings from studies of the elderly provide valuable information. Third, inadequate sample sizes often hamper the usefulness of research on the spinal cord disabled. Drawing valid conclusions from these small studies, especially concerning potential risk factors is difficult. To address these three problems, we critically evaluated the medical, nursing, and nutritional research literature that pertained to risk factors for pressure ulcer development. The purpose of this paper is to provide a review of published reports on the principal risk factors for pressure ulcers in persons with spinal cord injury.
\end{abstract}

Keywords: pressure ulcer; decubitus ulcer; spinal cord injuries; paralysis; risk factors; spinal cord injury complications

\section{Introduction}

Pressure ulcers are an underestimated healthcare problem, particularly for individuals with spinal cord injury. ${ }^{1,2}$ Prevention of pressure ulcers, therefore, has not been given the appropriate high priority. ${ }^{2 a}$ Each year in the United States, pressure ulcer-related complications cause 60,000 deaths. ${ }^{3}$ Among spinal cord injured individuals, between $7 \%$ and $8 \%$ will die of these complications. ${ }^{4,5}$

The annual incidence of pressure ulcers among individuals with SCI is between $23 \%{ }^{6}$ and $30 \%,{ }^{7}$ but up to $85 \%$ of SCI individuals develop a pressure ulcer at some point during their lifetimes. ${ }^{8-12}$ More than $70 \%$ of SCI patients with a pressure ulcer have multiple ulcers. ${ }^{3}$

Because a spinal cord injury drastically alters a person's physiology, 5,7,14-21 an understanding of the most appropriate risk factors for this population is required. Moreover, the cutoff points reflecting the unique thresholds for each of these risk factors must be established. ${ }^{22-24}$

Correspondence: DW Byrne at Byrne Research, 17 Dogwood Drive, Ridgefield, CT 06877-2707, USA
This review focuses on the major risk factors (Table 1) for the development of pressure ulcers in spinal cord injured individuals. ${ }^{25}$ Additional risk factors, described in the published literature, are listed in Tables 2-7. Discussion of these additional risk factors is beyond the scope of this review. Readers interested in the additional factors can refer to the original sources, or the more general review of pressure ulcers provided by Yarkony. ${ }^{78 \mathrm{~b}}$

\section{Pressure ulcer risk assessment scales}

The overwhelming number of risk factors reported in the literature poses a challenge in clinical applications. To focus attention on the major risk factors various scales for assessing pressure ulcer risk have been proposed. Unfortunately these scales have been of uncertain application for SCI patients.

The Norton Scale, ${ }^{79}$ one of the first of these pressure ulcer scoring systems, was developed in 1962, based on 250 geriatric patients. For the following 33 years, researchers refined and tested the Norton Scale on various types of patients. ${ }^{3,45,80-82}$ It 
accurately predicts pressure ulcers in orthopaedic patients ${ }^{83,84}$ but its use in other patients has resulted in only limited success. ${ }^{85-91}$

In 1973, the Gosnell Scale was developed using 30 elderly patients. ${ }^{28,29}$ The Braden Scale, developed in 1987, based on 199 patients, ${ }^{47}$ proved an accurate predictor in several studies, ${ }^{30,31,92}$ yet validation studies $^{32,53,70,74,86,93,94}$ did not confirm these results. In fact, one study showed that nurses could intuitively predict which patients would develop pressure ulcers more accurately than the Braden Scale. ${ }^{32}$ Although many other pressure ulcer scales and assessment systems have been mentioned in the literature, $26,39,58,95-107$ none have been proven effective in the SCI population.

Table 1 Major risk factors for pressure ulcers

\begin{tabular}{ll} 
Severity & of Spinal Cord Injury \\
1. & Decreased level of activity \\
2. & Immobility \\
3. & Completeness of the SCI \\
4. & Urine incontinence/moisture \\
5. & Autonomic dysreflexia/severe spasticity \\
Preexisting Conditions \\
$6 . \quad$ Advanced age \\
$7 . \quad$ Tobacco use/smoking \\
8. $\quad$ Pulmonary disease \\
9. $\quad$ Cardiac disease/abnormal electrocardiogram \\
10. $\quad$ Diabetes/poor glycemic control \\
11. $\quad$ Renal disease \\
12. Impaired cognitive function \\
13. $\quad$ Residing in a nursing home/hospital \\
Malnutrition and Anemia \\
$14 . \quad$ Hypoalbuminemia/hypoproteinemia \\
$15 . \quad$ Anemia \\
\hline
\end{tabular}

Table 2 Potential physical risk factors

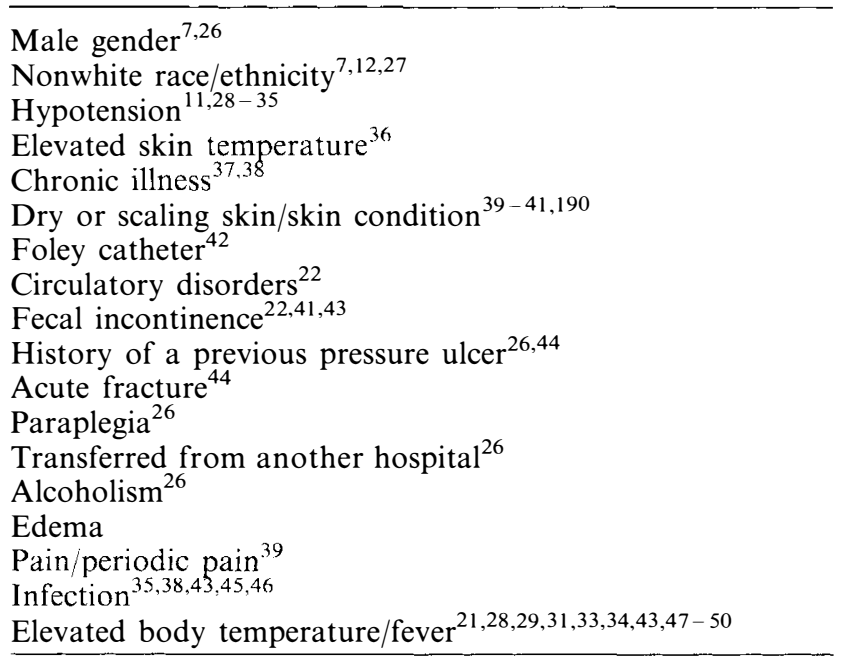

The variables in current risk assessment scales have been criticized as 'peripheral to the issue, subjectively determined and not correlated with the development of a pressure ulcer'. ${ }^{85}$ These scales often depend on vaguely defined and arbitrarily weighted risk factors. Although these pressure ulcer scales have been used for SCI individuals, ${ }^{45}$ we are not aware of any scale that was specifically designed for the SCI group.

Few SCI care givers want another scoring system. Most realize, however, a need to focus on major risk factors specific to the SCI population: without properly accounting for these major risk factors or the patient mix, predicting the high-risk subgroup will remain inaccurate. Researchers know that without proper adjustment for these major risk factors, evaluating methods of preventing pressure ulcers will be inefficient. ${ }^{8,108-116}$

Much of the published research on predicting those at risk for pressure ulcers, especially in persons with $\mathrm{SCI}$, is limited. Small sample sizes, inadequate follow-

Table 3 Potential nutritional risk factors

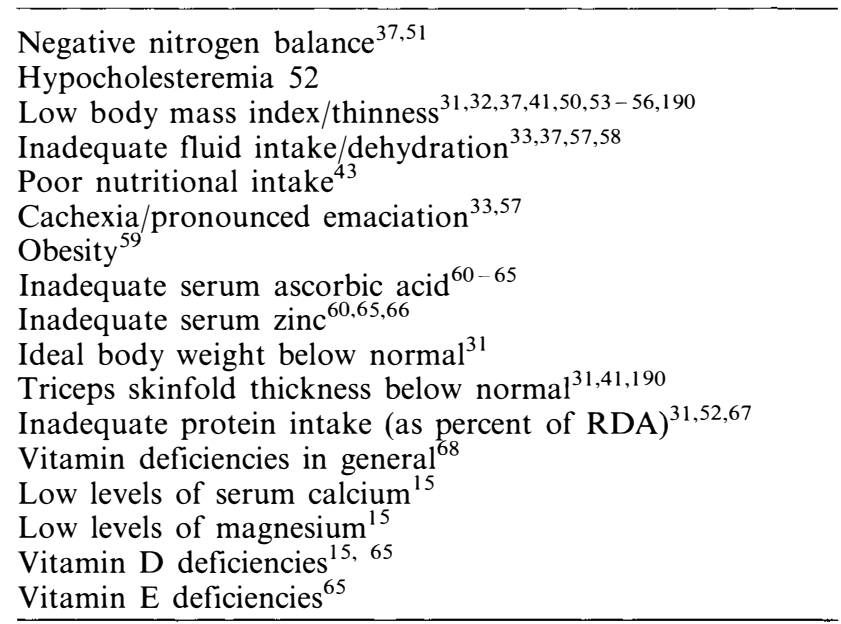

Table 4 Potential movement risk factors

Prolonged immobilization immediately after $\mathrm{SCI}^{11,69}$ Prolonged time on spinal board ${ }^{11}$ Friction $^{5,70,189}$

Shearing of skin surfaces ${ }^{37,70-72}$

Table 5 Potential socioeconomic risk factors

Low level of education 7,26
Low level of income
Poor hygiene
Medicare/Medicaid


Table 6 Potential psychological risk factors

Patient noncompliance with pressure ulcer prevention ${ }^{74}$ Uncooperative behavior ${ }^{39}$

Emotional stress ${ }^{75,76}$

Marital status of single/unmarried ${ }^{7}$

Poor responsibility in skin care ${ }^{77}$

Low satisfaction with activities of life $^{77}$

Low self-esteem ${ }^{78}$

Table 7 Potential medication risk factors

Medication in general $^{29,37}$

Sedatives ${ }^{28,39}$

Tranquilizers $^{28}$

Analgesics ${ }^{28}$

Steroids ${ }^{50}$

Anti-inflammatory drugs

Anesthesia

Cardiotonics $^{28}$

ups and insufficient control of confounding variables make generalizing difficult. Yarkony and Heinemann ${ }^{116 a}$ provide a notable exception in their large, long-term study of pressure ulcers. They showed that admission to a 'Model SCI Center' may significantly reduce the incidence of pressure ulcers. ${ }^{7,116 a}$ If pressure ulcers are to be prevented, understanding the major risk factors and using a system that accurately predicts the high-risk group among SCI individuals is critical.

\section{Severity of spinal cord injury}

Level of activity is a primary risk factor for pressure ulcer development. ${ }^{27-29,37,42,43,47,49,58,60,70,74,78,79,92 \text {, }}$ $117-120,189$ However, because approximately $90 \%$ of SCI patients use a wheelchair, ${ }^{25}$ this variable by itself is not a good discriminator.

Level of mobility is another important risk factor, independent of level of activity. ${ }^{12,22,27-29,33,37,38,41,45 \text {, }}$ $47-40,57,58,70,74,78,79,89,121,122-125,190^{\circ}$

The risk of ulcer formation in SCI patients, in the 'slightly' and 'very limited' mobility groups is similar. ${ }^{25}$ These ambiguous categories have been a major source of reliability errors, ${ }^{85}$ and in SCI patients they may not be essential for establishing the level of risk.

Completeness of spinal cord injury is a major risk factor. $7,9,26,44,69,126-128$ Young et al. reported the completeness of the injury appears to be a much more powerful determinant of pressure ulcer occurrence than level of the lesion'. ${ }^{7}$ This may be a function of the higher level of activity in paraplegics. Whether the risk of pressure ulcers is higher in tetraplegics or paraplegics remains unresolved. ${ }^{9,129}$ Many clinicians believe that higher spinal cord injuries (ie, cervical) are associated with higher risk of pressure ulcers. The weight of evidence does not support this. ${ }^{9,60,77,126,130}$ In fact, our experience suggests that patients with thoracic lesions are at the highest risk for pressure ulcers. $^{25}$ Because of these inconsistencies regarding paraplegia as a risk factor we did not include it as a major risk factor in Table 1. Instead, it is listed in Table 2 with other potential physical risk factors.

Incontinence and moisture have been consistently associated with pressure ulcers. $4,27,33,37,43,47,49,56-$ $58,62,70,74,78,79,81,92,94,118,122,125,131-139$ Urinary incontinence may be a more accurate predictor of pressure ulcers than fecal incontinence among the SCI patients. ${ }^{25}$ Unlike geriatric patients, fecal incontinence may not significantly increase the risk of pressure ulcers (independently of urinary incontinence) for SCI persons. Therefore, it also is listed in Table 2 with other potential physical risk factors rather than major risk factors in Table 1.

Autonomic dysreflexia is a condition that affects individuals with spinal cord injuries at level T6 and higher. This condition is the result of increased autonomic activity resulting from reflex hyperactive sympathetic responses to various provoking stimuli. Autonomic dysreflexia and spasticity 4,7,14,38,45,68,132, $140-143$ are both more common in patients who develop pressure ulcers, but the causal effect relationship is poorly understood.

\section{Preexisting conditions}

Age is a risk factor for pressure ulcers in the non-SCI population. ${ }^{27-29,31,32,34,37,42,57,60,79,84,120,127,144,145,190}$ The age cutoff point, however varies widely in the literature $\left(>40,{ }^{26}>50,{ }^{123} \geqslant 60,{ }^{44} \geqslant 65,43,49,123,144\right.$ $\left.>70,{ }^{27,33,40,70,119,120,134}>75,{ }^{41,190}>80,{ }^{49,146}\right)$ and may not be appropriate for SCI patients. The risk of pressure ulcers in SCI patients may increase after age 35 and again after age $65 .{ }^{25}$ For the pressure ulcer risk in the SCI population, age may have a bimodal curve.

Cigarette smoking plays a crucial role in the development of pressure ulcers. Current smokers are at significantly increased risk for pressure ulcers. $^{25,40,53,147}$ Pressure ulcers of the heel are four times more common in smokers. ${ }^{75}$ In a study of 38 SCI patients, cigarette smoking (pack-years) was positively correlated $(r=0.47, \quad P<0.001)$ with a 'higher incidence and more extensive pressure ulcers'. ${ }^{126}$ Fortunately, those who cease smoking may significantly reduce their risk of developing pressure ulcers and the effects of smoking may be partially reversible. $^{25}$

Arteriosclerotic heart disease is another pressure ulcer risk factor. ${ }^{1,73,117,120,148}$ Surprisingly, one study found a lower risk for pressure ulcers in those with heart disease. The authors that suggested this may be an artifact related to the sudden deaths in the patients with heart disease. ${ }^{40}$ Researchers have generally found that the incidence of pressure ulcers is higher in patients with cardiac diseases. $22,49,53,73,120,149,150$ This connection needs further investigation before it can be 
used to predict pressure ulcers accurately. Blood pressure is routinely higher in tetraplegics than in paraplegics. ${ }^{6}$ Chronic hypertension is more prevalent in SCI patients, compared with persons without spinal cord injury. ${ }^{19}$ These may be compensatory mechanisms because hypotension is a well-known risk factor for pressure ulcers. ${ }^{11,28,30,31,34}$

Another preexisting condition associated with pressure ulcers is pulmonary disease, but the causal mechanism is also not fully understood; ${ }^{7,25,43,59,151}$ future research should include blood gases and other methods of measuring the extent of pulmonary diseases in strong prospective designs.

SCI patients have a higher incidence of diabetes than non-SCI patients. ${ }^{19}$ Diabetes has been linked to pressure ulcers in many studies, $1,27,42,43,54,117,121$, $124,152,153$ but not in all. ${ }^{40,146}$ A link between renal disease and pressure ulcers has been suggested but never firmly established due mainly to limited sample size. $20,27,43,48,120,149,151$

Many of the studies that examined preexisting conditions lacked the statistical power to show the association between these conditions and pressure ulcers. For example, in a study of non-SCI hospitalized patients, Allman, et al. ${ }^{48}$ reported that the incidence of diabetes was twice as high $30 \%$ vs $15 \%)$ in a group of pressure ulcer patients $v s$ controls. The $P$ value was of borderline significance $(0.09)$ due to the small sample size of 108 patients. We calculated the sample size required to achieve statistical significance (using an alpha error of 0.05 and a power of 0.80 ) for the increase from $15 \%$ to $30 \%$. Such a study would require 134 patients with pressure ulcers and 134 patients without pressure ulcers. However, in smaller studies, lack of statistical significance should not be misinterpreted as proof that a variable is not a risk factor.

Another category of major risk factors involves inpaired cognitive function. Unconscious patients are at a higher risk of developing pressure ulcers than are semiconscious patients. ${ }^{27}$ Altered level of consciousness, history of cerebrovascular accident, and dementia have also been associated with pressure ulcers. $^{28,29,33,42,43,48,58,79,94,96,117,120,121}$ Although depression may be more prevalent in the SCI population, it is not related to pressure ulcers. ${ }^{154}$ Others have found psychosocial factors, ${ }^{77}$ such as economic selfesteem and social adjustment, ${ }^{155}$ to be related to pressure ulcers in SCI patients.

SCI patients in nursing homes and hospitals commonly have conditions that place them at increased risk for pressure ulcers. ${ }^{7,127}$ For non-SCI persons, the prevalence of pressure ulcers varies widely among nursing homes - independent of the population's injury severity. ${ }^{55,156,157}$ The prevalence of pressure ulcers in nursing homes has been reported to range from $0 \%$ to $15 \%,{ }^{55} 16 \%$ to $35 \%,{ }^{94} 2.6 \%$ to $24 \%{ }^{158}$ and $0 \%$ to $78 \%{ }^{156}$ In a study performed in 30 Department of Veterans Affairs nursing homes, investigators found that the injury severity of patients was similar in the two institutions with the extreme pressure ulcer prevalence rates. ${ }^{55}$ For an SCI individual, residing in a nursing home or hospital is a good indicator of risk for pressure ulcers regardless of the causal relationship.

\section{Malnutrition and anemia}

Pressure ulcer risk increases with poor nutrition. After pressure itself, malnutrition is one of the most important risk factors in the etiology of pressure ulcers. $^{24,26,28,29,37,42,47,48,51,52,59,62,121,138,159-167}$ Breslow ${ }^{168}$ reviewed the research literature between 1943 and 1989 and concluded 'The literature clearly demonstrates that patients with pressure ulcers are malnourished'. In particular, the published reports show that hypoalbuminemia and anemia clearly predispose patients to pressure ulcers

In a comparison study, physician-assessed nutritional status was not a good predictor of pressure ulcer development; low hemoglobin $(<12 \mathrm{gm} / \mathrm{dl})$ was found to be a significant predictor, ${ }^{40}$ demonstrating the importance of using objective nutritional indicators. Judging that a patient has 'inadequate nutrition' may be more convenient than measuring hemoglobin or serum albumin value. Unfortunately, this subjective assessment has little predictive value. ${ }^{22}$ The cost of blood analysis for objectively measuring the nutritional status of these patients is only a small fraction of the cost of treating a pressure ulcer. ${ }^{170}$

Hypoalbuminemia has been well documented as a

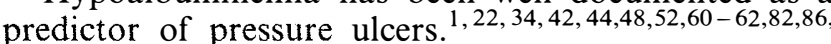
$92,108,117,118,121,132,133,149,160-163,170-174$

Hypoproteinemia 1 14, 22, 31, 34, 38, 42, 45, 86, 121, 161, 164, 172, 175-177 has also been linked to pressure ulcer development. Holmes, et al. ${ }^{170}$ studied nine patients who developed pressure ulcers after admission. They examined changes from admission to ulcer formation and found significant drops in albumin (3.1 to $2.5 \mathrm{gm} /$ dl) and hemoglobin (12.6 to $8.7 \mathrm{gm} / \mathrm{dl})$. These findings and other evidence suggest that hypoalbuminemia is an antecedent factor and not the result of a pressure ulcer. $25,34,48,82$

One study does not completely support this view. In 1989 , Berlowitz and Wilking ${ }^{42}$ found that hypoalbuminemia was significantly associated with pressure ulcers in their cross-sectional analysis, but not in their prospective analysis. Yet the lack of statistical significance in the prospective design does not - as they suggested - disprove hypoalbuminemia as a risk factor or prove a bias in the cross-sectional study. This lack of significance could be the result of too few patients with pressure ulcers $(n=20$ compared with $n=100$ for the cross-sectional study). It also could be attributable to the short follow-up period of 3 weeks. There is also evidence that hypoalbuminemia may be associated with deep, but not superficial pressure ulcers. $^{73,121,161}$ Nursing staff may provide different care (such as nutritional supplementation or more 
frequent turning) to those with abnormally low albumin levels. This would obviously bias the findings of these inhospital prospective studies.

Several reports suggest that for serum albumin a cutoff point of $<3.4 \mathrm{gm} / \mathrm{dl}$ may be an appropriate threshold. Bobel ${ }^{173}$ states, 'Serum albumin levels below $3.4 \mathrm{mg}$ per $\mathrm{dl}$ are significant for protein deficiency'. ${ }^{170}$ Others have recommended starting nutritional intervention to prevent pressure ulcers when the albumin level is below $3.3 \mathrm{gm} / \mathrm{dl} .{ }^{161}$ Holmes ${ }^{170}$ et al. showed that patients with albumin levels below $3.5 \mathrm{gm} / \mathrm{dl}$ were nearly five times as likely to develop a pressure ulcer. They recommended this cutoff point for screening patients for pressure ulcer risk upon hospital admission. In a study by Vasile et al., ${ }^{1}$ serum albumin levels were below $3.5 \mathrm{gm} / \mathrm{dl}$ for all 27 patients with pressure ulcers. Moolten ${ }^{121}$ found serum albumin levels below $3.5 \mathrm{gm} / \mathrm{dl}$ in $85.7 \%(24 / 28)$ of patients with deep pressure ulcers. SCI patients have increased albumin elimination rates ${ }^{16}$ and lower serum albumin levels than non-SCI patients $(3.70 \mathrm{vs}$ $4.15 \mathrm{gm} / \mathrm{dl}, \quad P<0.001){ }^{15}$ Yet among pressure ulcer patients, SCI patients had a higher albumin level than non-SCI patients $(3.40$ vs $2.13 \mathrm{gm} / \mathrm{dl}){ }^{22}$ Individuals with SCI require a cutoff point, specific for their condition. ${ }^{25}$

Anemia is also a well-established antecedent of

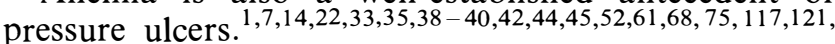
$132,170,178-181$ Hematocrit values of less than $36 \%$ may be useful for screening patients at risk, although the optimal hematocrit level for SCI patients may be greater than $40 \%{ }^{25}$ Cutoff points of $<36 \%$ for hematocrit and $<12 \mathrm{gm} / \mathrm{dl}$ for the hemoglobin are supported by several published studies. ${ }^{40,52,68,143}$

The total number of pressure ulcers that a SCI person develops is inversely related to hematocrit level. ${ }^{25}$ Yet average hematocrit and albumin levels are often within normal limits for SCI individuals in both groups - with and without pressure ulcers. Nevertheless these groups can be significantly different, statistically, from one another. ${ }^{25}$ Several explanations for this paradox can be found. First, mild anemia is only one of many factors that predispose SCI individuals to pressure ulcers. Second, low hematocrit may be a strong risk factor for some sites (eg, trochanteric pressure ulcers) but a weak factor for pressure ulcers at other sites. Third, it is possible that SCI patients have a different hematocrit threshold for pressure ulcer development than non-SCI patients. In addition most SCI patients experience mild anemia and many have 'unpredictable fluctuations of the hemoglobin level'. ${ }^{165}$

The 'traditional' surgical cutoff point for hematocrit is $<30 \%$, and for albumin is $<3.0 \mathrm{gm} / \mathrm{dl}$. These points are not based on scientific studies involving SCI patients, but are rather designed to identify surgical patients at risk for postoperative mortality. Our recent findings suggest that these two cutoff points would not be useful for screening SCI patients for pressure ulcer risk; specificity would be $100 \%$ but sensitivity would be below $10 \% .^{25}$ Among SCI patients, those with 'above normal' or 'high normal' hematocrit and albumin values may be protected against pressure ulcer development. Recently, a large study of the elderly showed that, even within the normal range for serum albumin, mortality risk increases 'stepwise' with decreasing albumin. ${ }^{182}$

Hypoalbuminemia and anemia both predict length of stay for SCI patients in a rehabilitation institution. ${ }^{181}$ Increasing hematocrit and albumin levels through nutritional supplementation does increase the rate of pressure ulcer healing. ${ }^{167,169,184,186}$ Low hematocrit is predictive of Stage III and IV pressure ulcers, but not Stage I and II. The mean hematocrit of the pressure ulcer group (for all stages) will not provide an accurate measure of this risk factor. Several reports have shown that Stage III and IV ulcers have different risk factors. ${ }^{52,73,12 \text { T, }} 161,163,178,183$

\section{Conclusions}

Pressure ulcers account for one-fourth of the cost of caring for SCI patients. ${ }^{132}$ Prevention of these ulcers would cost less than one-tenth the amount spent on treatment: ${ }^{135}$ clearly 'more emphasis must be placed on their prevention'. ${ }^{128}$ Changes in the health care system should include cost-efficient and timely prevention programs to contain these medical costs in the future.

The total cost attributable to treating pressure ulcers has been estimated at between two and five billion dollars annually in the United States. ${ }^{77,80,124,162}$ During the initial hospital and rehabilitation period, it costs 66 million dollars per year to treat new SCI patients who developed pressure ulcers $(40 \%$ of the 8275). ${ }^{11}$

In the US there are 200,000 SCI patients. ${ }^{2,186}$ The annual incidence of pressure ulcers in SCI patients is $23 \%{ }^{6}$ Thus, an estimated 46,000 SCI individuals per year develop a pressure ulcer in the US. Using a conservative estimate of $\$ 25,000$ to treat each pressure ulcer, ${ }^{187}$ the potential total cost of treating SCI patients for pressure ulcers can be estimated at $\$ 1.2$ billion annually.

Although cost estimates vary, there is no question that preventing pressure ulcers is far less expensive than treating them. ${ }^{3,135,188}$ Patients with multiple, major risk factors are in a high-risk group and should be enrolled in a comprehensive program for preventing pressure ulcers. ${ }^{109}$ Pressure ulcer prevention in the high-risk group of SCI patients deserves a high priority in the future health care and insurance reforms. $^{7}$ This review summarizes the published information on the 15 major risk factors to help make such a prevention program more manageable.

\section{Acknowledgements}

Supported in part by grants from the New York State Department of Health, the Centers for Disease Control 
and Prevention, and the Eastern Paralyzed Veterans Association. The authors thank Mr Paul van Niewerburgh.

\section{References}

1 Vasile J, Chaitin H. Prognostic factors in decubitus ulcers of the aged. Geriatrics 1972; 27: 126-129.

2 Stover SL, Fine PR, eds. Spinal cord injury: the facts and figures. Birmingham: University of Alabama at Birmingham, 1986.

2a Panel for the Prediction and Prevention of Pressure Ulcers in Adults. Pressure Ulcers in Adults: Prediction and Prevention. Clinical Practice Guideline, Number 3. AHCPR Publication No. 92-0047. Rockville, MD: Agency for Health Care Policy and Research, Public Health Service, U.S. Department of Health and Human Services. May 1992.

3 Kynes PM. A new perspective on pressure sores prevention. $J$ Enterost Ther 1986; 13: $42-43$.

4 Reuler JB, Cooney TG. The pressure sore: pathophysiology and principles of management. Ann Intern Med 1981; 94: 661666.

5 Dinsdale SM. Decubitus ulcers: role of pressure and friction in causation. Arch Phys Med Rehabil 1974; 55: 147 - 152.

6 Whiteneck GG et al. Mortality, morbidity, and psychosocial outcomes of persons spinal cord injured more than 20 years ago. Paraplegia 1992; 30: 617-630.

7 Young JS, Burns PE. Pressure sores and the spinal cord injured: part II. Model Systems'. SCI Digest 1981; 3: 11-26, 48 .

8 DeLateur BJ et al. Wheelchair cushions designed to prevent pressure sores: an evaluation. Arch Phys Med Rehabil 1976; 57: $129-134$.

9 Richardson RR, Meyer Jr. PR. Prevalence and incidence of pressure sores in acute spinal cord injuries. Paraplegia 1981; 19: $235-247$.

10 Spence WR, Burk RD, Rae JW. Gel support for prevention of decubitus ulcers. Arch Phys Med Rehabil 1967; 48: 283-288.

11 Mawson AR et al. Risk factors for early occurring pressure ulcers following spinal cord injury. Am J Phys Med Rehabil 1988; 67: 123 - 127 .

12 Fuhrer MJ et al. Pressure ulcers in community-resident persons with spinal cord injury: prevalence and risk factors. Arch Phys Med Rehabil 1993; 74: $1172-1177$

13 Poer DH. Newer concepts in treatment of paralyzed patients due to war-time injuries of spinal cord. Ann Surg 1946; 123: $510-514$.

14 Narsete TA, Orgel MG, Smith D. Pressure sores. Am Fam Physician 1983; 28: $135-139$.

15 Zhou XJ et al. Effects of chronic spinal cord injury and pressure ulcer on 25(OH)-vitamin D levels. J Am Paraplegia Soc 1992; 16: $9-13$.

16 Ring $\mathrm{J}$ et al. Elimination rate of human serum albumin in paraplegic patients. Paraplegia 1974; 12: $139-144$.

17 Rodriguez GP, Claus-Walker J. Biochemical changes in skin composition in spinal cord injury: a possible contribution to decubitus ulcers. Paraplegia 1988; 26: $302-309$.

18 Ditunno Jr JF, Formal CS. Chronic spinal cord injury. $N$ Engl J Med 1994; 330: 550- 556.

19 Nakajima A et al. The disease pattern and causes of death of spinal cord injured patients in Japan. Paraplegia 1989; 27: $163-171$.

20 Barton CH, Vaziri ND, Gordon S, Tilles S. Renal pathology in end-stage renal disease associated with paraplegia. Paraplegia 1984; 22: $31-41$.

21 Daniel RK, Priest DL, Wheatley DC. Etiologic factors in pressure sores: an experimental model. Arch Phys Med Rehabil 1981; 62: $492-498$

22 Shannon ML, Skorga P. Pressure ulcer prevalence in two general hospitals. Decubitus 1989; 2: $38-43$.

23 Munro D. Care of the back following spinal-cord injuries - a consideration of bed sores. N Engl J Med 1940; 223: 391-398.
24 Bogie KM, Nuseibeh I, Bader DL. New concepts in the prevention of pressure sores. In: Frankel HL (ed). Handbook of Clinical Neurology - Spinal Cord Trauma. 1992, Volume 17 pp. $347-366$.

25 Salzberg CA et al. A new pressure ulcer risk assessment scale for individuals with spinal cord injury. Am J Phys Med Rehabil 1996 (In press).

26 Vidal J, Sarrias M. An analysis of the diverse factors concerned with the development of pressure sores in spinal cord injured patients. Paraplegia 1991; 29: $261-267$.

27 Manley MT. Incidence, contributory factors, and cost of pressure sores. South African Medical Journal 1978; 53: 217 222.

28 Gosnell DJ. An assessment tool to identify pressure sores. Nurs Res 1973; 22: $55-59$.

29 Gosnell DJ. Pressure sore risk assessment - a critique Part I The Gosnell Scale. Decubitus 1989; 2: $32-38$.

30 Bergstrom N, Demuth PJ, Braden BJ. A clinical trial of the Braden Scale for predicting pressure sore risk. Nurs Clin N Am 1987; 22: $417-428$.

31 Bergstrom N, Braden B. A prospective study of pressure sore risk among institutionalized elderly. J Am Geriatr Soc 1992; 40: $747-758$.

32 Salvadalena GD, Snyder ML, Brogdon KE. Clinical trial of the Braden Scale on an acute care medical unit. J ET Nurs 1992; 19: $160-165$.

33 Parish LC, Witkowski JA, Crissey JT. The Decubitus Ulcer Masson Publishing USA, Inc: New York. Year Book Medical Publishers, Inc: Chicago. 1983.

34 Bergstrom $\mathrm{N}$ et al. Diminished tissue tolerance: influence on pressure sore development in the institutionalized elderly. Appl Nurs Res 1988; 1: 96.

35 Ryan TJ. Blood supply and decubitus ulcers. Int J Dermatol 1979; 18: $123-124$

36 Fisher SV, Szymke TE, Apte SY, Kosiak M. Wheelchair cushion effect on skin temperature. Arch Phys Med Rehabil 1978; 59: $68-72$.

37 Gosnell DJ. Pressure sore risk assessment - Part II - analysis of risk factors. Decubitus 1989; 2: $40-43$.

38 Talbot HS. Adjunctive care of spinal cord injury. Surg Clin $N$ Am 1968; 48: $737-757$.

39 Pritchard V. Pressure sores - calculating the risk. Nurs Times 1986; 82: $59-61$.

40 Guralnik JM, Harris TB, White LR, Coroni-Huntley JC Occurrence and predictors of pressure sores in the National Health and Nutrition Examination survey follow-up. $\mathrm{J} \mathrm{Am}$ Geriatr Soc 1988; 36: 807-812.

41 Allman RM et al. Pressure ulcer risk factors among hospitalized patients with activity limitations. JAMA 1995; 273: $865-870$.

42 Berlowitz DR, Wilking SVB. Risk factors for pressure sores: a comparison of cross-sectional and cohort-derived data. $\mathrm{J} \mathrm{Am}$ Geriatr Soc 1989; 37: $1043-1050$.

43 Piloian BB. Defining characteristics of the nursing diagnosis 'high risk for impaired skin integrity'. Decubitus 1992; 5: 32 42.

44 Rochon PA et al. Risk assessment for pressure ulcers: an adaptation of the National Pressure Ulcer Advisory Panel risk factors to spinal cord injured patients. J Am Paraplegia Soc 1993; 16: $169-177$.

45 Dowling AS. Pressure sores - their cause, prevention, and treatment. Md State Med J 1970; 19: 131-134.

46 Williams A. A study of factors contributing to skin breakdown. Nurs Res 1972; 21: 238-243.

47 Bergstrom N, Braden BJ, Laguzza A, Holman V. The Braden Scale for Predicting Pressure Sore Risk. Nurs Res 1987; 36: $205-210$.

48 Allman RM et al. Pressure sores among hospitalized patients. Ann Intern Med 1986; 105: 337 - 342.

49 Ek AC, Boman G. A descriptive study of pressure sores: the prevalence of pressure sores and the characteristics of patients. J Adv Nurs 1982; 7: 51-57. 
50 Williams A. A study of factors contributing to skin breakdown. Nurs Res 1972; 21: $238-243$.

51 Wroblewski JJ. The nutritional aspect of pressure ulcer care. Ostomy/Wound Manage 1986; 13: 18 - 36.

52 Breslow RA, Hallfrisch J, Goldberg AP. Malnutrition in tubefed nursing home patients with pressure sores. J Parenter Enteral Nutr 1991; 15: $663-668$.

53 Langemo DK et al. Incidence and prediction of pressure ulcers in five patient care settings. Decubitus 1991; 4: 25-36.

54 Batson S, Adam S, Hall G, Quirke S. The development of a pressure area scoring system for critically ill patients: a pilot study. Intensive Crit Care Nurs 1993; 9: 146 - 151.

55 Rudman D et al. Comparison of clinical indicators in two nursing homes. J Am Geriatr Soc 1993; 41: 1317-1325.

56 Irvine RE. Norethandrolone and prevention of pressure sores. Lancet 1961; 2: 1333.

57 Andersen KE, Jensen O, Kvorning SA, Bach E. Prevention of pressure sores by identifying patients at risk. Br Med J (Clin Res Ed.) 1982; 284: 1370-1371.

58 Abruzzese RS. Early assessment and prevention of pressure sores. In: Lee BY (ed). Chronic Ulcers of the Skin. McGrawHill, NY: New York, 1985, pp. 1-19.

59 Agarwal N, Del Guercio LRM, Lee BY. The role of nutrition in the management of pressure sores. In: Chronic Ulcers of the Skin. Lee BY (ed). McGraw-Hill, NY, New York 1985. pp. $133-145$.

60 Braden B, Bergstrom N. A conceptual schema for the study of the etiology of pressure sores. Rehab Nurs 1987; 12: 8-12,16.

61 Burr RG, Rajan KT. Leucocyte ascorbic acid and pressure sores in paraplegia. Br J Nutr 1972; 28: $275-281$

62 Maklebust J. Pressure ulcers: etiology and prevention. Nurs Clin N Amer 1987; 22: 359-377.

63 Hunter T, Rajan KT. The role of ascorbic acid in the pathogenesis and treatment of pressure sores. Paraplegia 1971; 8: $211-215$.

64 Mattews LE. Pressure sores: nutrition care's vital role. J Nutr Elderly 1989; 8: $107-112$.

65 Balch JF, Balch PA. Prescription for nutritional healing. Avery, Garden City Park: NY. 1990, pp. 103-104.

66 Burr RG. Blood zinc in the spinal patient. J Clin Path 1973; 26: $773-775$.

67 Breslow RA, Bergstrom N. Nutritional prediction of pressure ulcers. J Am Diet Assoc 1994; 94: 1301 - 1304.

68 Merlino AF. Decubitus ulcers - cause, prevention, and treatment. Geriatrics 1969; 24/12: 119-124.

69 Curry K, Casady L. The relationship between extended periods of immobility and decubitus ulcer formation in the acutely spinal cord-injured individual. J Neurosci Nurs 1992; 24: 185 189.

70 Oot-Giromini BA. Pressure ulcer prevalence, incidence and associated risk factors in the community. Decubitus 1993; 6: $24-32$.

71 Reichel S. Shearing force as a factor in decubitus ulcers in paraplegics. J Amer Med Assoc 1958; 166: $762-763$.

72 Bennett L et al. Skin blood flow in seated geriatric subjects. Arch Phys Med Rehab 1981; 62: 392 - 398.

73 Berecek KH. Etiology of decubitus ulcers. Nurs Clin N Am 1975; 10: $157-170$.

74 Copeland-Fields LD, Hoshiko BR. Clinical validation of Braden and Bergstrom's conceptual schema of pressure sore risk factors. Rehabil Nurs 1989; 14: $257-260$.

75 Barton AA. Prevention of pressure sores. Nurs Times 1977; 73: $1593-1595$

76 Krouskop TA. A synthesis of the factors that contribute to pressure sore formation. Medical Hypotheses 1983; 11: $255-$ 267.

77 Anderson TP, Andberg MM. Psychosocial factors associated with pressure sores. Arch Phys Med Rehabil 1979; 60: 341-346.

78 Gosnell DJ. Assessment and evaluation of pressure sores. Nurs Clin N Am 1987; 22: 399-415.

78b Yarkony GM. Pressure ulcers: a review. Arch Phys Med Rehabil 1994; 75: $908-917$.
79 Norton D, McLaren R, Exton-Smith AN. An investigation of geriatric nursing problems in hospital. The National Corporation for the Care of Old People: London, 1962. Reprinted by Churchill Livingston: Edinburgh, 1975, pp. 193-238.

80 Hodge J, Mounter J, Gardner G, Rowley G. Clinical trial of the Norton Scale in acute care settings. Aust J Adv Nursing 1990; 8: $39-46$.

81 Goldstone LA, Goldstone J. The Norton score: an early warning of pressure sores? J Adv Nurs 1982; 7: 419-426.

82 Ek AC. Prediction of pressure sore development. Scand $J$ Caring Sci 1987; 1: 77-84.

83 Goldstone LA, Roberts BV. A preliminary descriminant function analysis of elderly orthopaedic patients who will or will not contract a pressure sore. Int J Nurs Stud 1980; 17: $17-$ 23.

84 Roberts BV, Goldstone LA. A survery of pressure sores in the over sixties on two orthopaedic wards. Int J Stud 1979; 16: $355-364$.

85 Lincoln $\mathrm{R}$ et al. Use of the Norton Pressure Sore Risk Assessment Scoring System with elderly patients in acute care. J Enterstom Ther 1986; 13: 132-138.

86 Kemp MG, Keithley JK, Smith DW, Morreale B. Factors that contribute to pressure sores in surgical patients. Res Nurs Health 1990; 13: $293-301$.

87 Hicks DJ. An incidence study of pressure sores following surgery. ANA Clinical sessions proceedings, Geriatric Nursing: Miami, FL, 1970, pp. 49-54.

88 Vermillion C. Operating room acquired pressure ulcers. Decubitus 1990; 3: 26-30.

89 van Marum RJ, Germs P, Ribbe MW. The Norton decubitus risk score in a nursing home. Tijdschr-Gerontol-Geriatr [Dutch] 1992; 23: 48 - 53.

90 Xakellis GC et al. A comparison of patient risk for pressure ulcer development with nursing use of preventive interventions. J Amer Geriatr Soc 1992; 40: 1250-1254.

91 Ek AC, Bjurulf P. Interrater variability in a modified Norton Scale. Scand J Caring Sci 1987; 4: 99-102.

92 Bergstrom N, Demuth PJ, Braden BJ. A clinical trial of the Braden Scale for predicting pressure sore risk. Nurs Clin N Amer 1987; 22: 417-428.

93 Xakellis GC et al. A comparison of patient risk for pressure ulcer devlopment with nursing use of preventive interventions. J Am Geriatr Soc 1992; 40: 1250 - 1254.

94 Burd C et al. Skin problems: epidemiology of pressure ulcers in a skilled care facility. J Gerontol Nurs 1992; 18: 29-39.

95 Knoll Pharmaceutical Company. The Knoll Scale of liability to pressure sores. In JK McFarlane, G. Casteldine (eds). A guide to the practice of nursing using the nursing process. CV Mosby Co, London: 1982.

96 Lowthian P. Practical nursing: turning clock system to prevent pressure ulcers. Nurs Mirror 1979; 148: $30-31$.

97 Jones PL, Millman A. A three-part system to combat pressure sores. Geriatr Nurs 1986; 7: 78-81.

98 Waterlow J. A risk assessment card. Nurs Times 1985; 81: 48 55.

99 Isler C. Old truths, and some new ideas. $R N$ 1972; Jul: $42-45$.

100 Flint Laboratories: Patient susceptibility to pressure sores. July 1978.

101 Dow B. Hickman, Inc: Skin care assessment guideline.

102 Meical Products Division/3M Center: Decubitus Ulcers: Classification, assessment, management. 1978.

103 Pharmacia Inc. The nurse's manual for documentation of lesion care: a systematic approach, by Suzanne DiMascia Joyner. March 1980.

104 Rampio E. Did we do that to him? J Pract Nurs 1976: June: 18 21.

105 Fowler E. Pressure sores: Prevention and nursing. A methodical approach to pressure sores. Columbia, Maryland: Dynamic dimensions in health care, 1980.

106 Kerr J, Sinson S, Shannon ML. Pressure sores: Distinguishing fact from fiction. Can Nurs, 1981; July/August: 23-28. 
107 Arnell I. Treating decubitus ulcers. Nursing '83 1983; June: 50 55.

108 Allman RM. Pressure ulcers. In Hazzard WR, Andres R, Bierman EL, Blass JP (eds). Principles of geriatric medicine and gerontology (2nd ed). New York, McGraw-Hill, 1990, chapter 125 , pp. $1204-1211$

109 Bliss M, McLaren R, Exton-Smith AN. Preventing pressure sores in hospital: controlled trial of a large-celled ripple mattress. Br Med J 1967; 1: 394-397.

110 Cumming WT, Tompkins WJ, Jones RM, Margolis SA. Microprocessor-based weight shift monitors for paraplegic patients. Arch Phys Med Rehab 1986; 67: 172 - 174.

111 Daechsel D, Conine TA. Special mattresses: effectiveness in preventing decubitus ulcers in chronic neurologic patients. Arch Phys Med Rehabil 1985; 66: 246-248.

112 Garber SL, Campion LJ, Krouskop TA. Trochanteric pressure in spinal cord injury. Arch Phys Med Rehabil 1982; 63: 549552.

113 Merbitz CT, King RB, Bleiberg J, Grip JC. Wheelchair pushups: measuring pressure relief frequency. Arch Phys Med Rehab 1985; 66: $433-439$.

114 Minns RJ, Sutton RA, Duffus A, Mattinson R. Underseat pressure distribution in the sitting spinal injury patient. Paraplegia 1984; 22: $297-304$.

115 Reichert H. Surgical treatment of pressure sores in paraplegics and possible prevention of their recurrence. Scand J Plast Reconstr Surg 1986; 20: 125-127.

116 Mikulic MA. Decubitus: an analysis of current methods of prevention and treatment. Arch Phys Med Rehabil (Academy/ congress abstract) 1977; 58: 516.

116a Yarkony GM, Heinemann AW. Pressure ulcers. In Stover SL, Whiteneck G, DeLisa J. (eds). Spinal Cord Injury. Clinical outcomes from the model systems, Maryland: Aspen Publishers, 1995. pp. $100-116$.

117 Dimant J, Tanael L. Decubitus ulcers: when to suspect osteomyelitis. Geriatrics 1987; 42: $74-83$.

118 Alvarez OM, Childs EJ. Pressure ulcers: physical, supportive, and local aspects of management. Clin Podiatr Med Surg 1991; 8: $869-890$.

119 Barbenel JC, Jordan MM, Nicol SM, Clarck MO. Incidence of pressure-sores in the Greater Glasgow Health Board area. Lancet 1977; 2: $548-550$.

120 Petersen NC, Bittmann S. The epidemiology of pressure sores. Scand J Plast Reconstr Surg 1971; 5: 62-66.

121 Moolten SE. Bedsores in the chronically ill patient. Arch Phys Med Rehabil 1972; 53: 430 - 438.

122 McCormick KA, Cella M, Scheve A, Engel BT. Costeffectiveness of treating incontinence in severely mobilityimpaired long term care residents. Qual Rev Bull 1990; 16:439443.

123 Nyquist R, Hawthorn PJ. The prevalence of pressure sores within an area health authority. $J$ Adv Nurs 1987; 12: $183-187$.

124 Trott A. Chronic skin ulcers. Emerg Med Clin North Am 1992; 10: $823-845$.

125 Exton-Smith AN, Sherwin RW. The prevention of pressure sores: significance of spontaneous bodily movements. Lancet 1961; 2: 1124.

126 Lamid S, El Ghatit AZ. Smoking, spasticity and pressure sores in spinal cord injured patients. Am J Phys Med 1983; 62: 300 306.

127 Thiyagarajan C, Silver JR. Aetiology of pressure sores in patients with spinal cord injury. Br Med J (Clin Res Ed.) 1984; 289: $1487-1490$

128 Knutsdottir S. Spinal cord injuries in Iceland 1973-1989-a follow-up study. Paraplegia 1993; 31: 68-72.

129 Wahle $\mathrm{H}$. Occurrence of pressure ulcers following discharge from the hospital of patients with complete paraplegia - a longterm follow-up study. Rehabilitation (Stuttgart, German) 1984; 23: $133-139$.

130 Lloyd EE, Baker F. An examination of variables in spinal cord injury patients with pressure sores. SCI Nurs 1986; 3: 19-22.

131 Hunter SM et al. Pressure ulcer prevalence and incidence in a rehabilitation hospital. Rehabil Nurs 1992; 17: $239-242$.
132 Houle RJ. Evaluation of seat devices designed to prevent ischemic ulcers in paraplegic patients. Arch Phys Med Rehabil 1969; 50: $587-594$.

133 Seiler WO, Stahelin HB. Decubitus ulceration in the elderly. In: Katz PR \& Calkins E (eds). Principles and practices of nursing home care New York: Springer, 1989. pp. 328-348.

134 Andersen KE, Kvorning SA. Medical aspects of the decubitus ulcer. Inter J Dermatol 1982; 21: 265-270.

135 Noble PC. The prevention of pressure sores in persons with spinal cord injuries. Monograph 11. International exchange of information in rehabilitation, New York. World Rehabilitation Fund, Inc., 400 East 34th Street, 10016. Pressure sore prevention program of the spinal injury unit, Royal Perth Rehabilitation Hospital in Western Australia, 1981.

136 Lee BY, Thoden WR. Surgical management of pressure sores. In: Lee By (ed). Chronic Ulcers of the skin McGraw-Hill, NY: New York 1985. pp. 147-170.

137 Flam E. Skin maintenance in the bed-ridden patient. Ostomy/ Wound Management 1990; 28: $48-54$.

138 Levine JM, Simpson M, McDonald RJ. Pressure sores: a plan for primary care prevention. Geriatrics 1989; 44: 75-90.

139 Hebel JR, Warren JW. The use of urethral, condom, and suprapubic catheters in aged nursing home patients. $J \mathrm{Am}$ Geriatr Soc 1990; 38: $777-784$.

140 Ferido T, Habel M. Spasticity in head trauma and CVA patients: etiology and management. J Neuroscience Nurs 1988; 20: $17-22$.

141 Putty TK, Shapiro SA. Efficacy of dorsal longitudinal myelotomy in treating spinal spasticity: a review of 20 cases. J Neurosurg 1991; 75: $397-401$.

142 Turnbull IM. Percutaneous lumbar rhizotomy for spasms in paraplegia. Paraplegia 1983; 21: 131-136.

143 Black JM, Black SB. Surgical management of pressure ulcers. Nurs Clin N Am 1987; 22: 429-438.

144 Gerson LW. The incidence of pressure sores in active treatment hospitals. Int J Nurs Stud 1975; 12: $201-204$

145 Kosiak M. Prevention and rehabilitation of pressure ulcers. Decubitus 1991; 4: 60-68.

146 Jensen TT, Juncker Y. Pressure sores common after hip operations. Acta Orthop Scand 1987; 58: $209-211$.

147 Salzberg CA. Smoking and pressure sores in spinal cord injured patients. American Paraplegia Society, 40th annual conference, Las Vegas, Nev, Sept 6-8, 1994 (poster presentation).

148 Husain T. An experimental study of some pressure effects on tissues with reference to the bed sore problem. J Path Bact 1953; 66: $347-358$

149 Schaab PC et al. Femoral neck fractures in patients receiving long-term dialysis. Clin Orthop 1990; Nov (260): 224-231.

150 Shetty KR, Duthie Jr EH. Thyrotoxicosis induced by topical iodine application. Arch Intern Med 1990; 150: 2400-2401.

151 Vaziri ND et al. Bacterial infections in patients with chronic renal failure: occurrence with spinal cord injury. Arch Intern Med 1982; 142: 1273 - 1276.

152 Miller III, OF. Essentials of pressure ulcer treatment - the diabetic experience. J Dermatol Surg Oncol 1993; 19: 759-763.

153 Rubin CF, Dietz RR, Abruzzese RS. Auditing the decubitus ulcer problem. Am J Nurs 1974; 74: 1820-1821.

154 Fuhrer MJ et al. Depressive symptomatology in persons with spinal cord injury who reside in the community. Arch Phys Med Rehabil 1993; 74: 255-260.

155 Gordon WA et al. The relationship between pressure sores and psychosocial adjustment in persons with spinal cord injury. Rehabil Psychol 1982; 27: 185-191.

156 Zinn JS, Aaronson WE, Rosko MD. Variations in the outcomes of care provided in Pennsylvania nursing homes. Med Care 1993; 31: 475-487.

157 Holmes JH 4th, Guileyardo JM, Barnard JJ, DiMaio VJ. Pressure sores in a Christian Science sanatorium. Am J Forensic Med Pathol 1993; 14: 10-11.

158 Brandeis GH et al. The epidemiology and natural history of pressure ulcers in elderly nursing home residents. J Amer Med Assoc 1990; 264: 2905 
159 The National Pressure Ulcer Advisory Panel. Pressure ulcers prevalence, cost and risk assessment: consensus development conference statement. Decubitus 1989; 2: 24-28.

160 Peiper B, Adams W, Mikols C, Mance B. Visceral protein nutritional assessment of patients placed on a high or low airloss bed. J Enterostom Ther 1990; 17: 145 - 149.

161 Pinchcofsky-Devin GD, Kaminski MV. Correlation of pressure sores and nutritional status. J Am Geriatr Soc 1986; 34: $435-440$.

162 Natow AB. Nutrition in prevention and treatment of decubitus ulcers. Top Clin Nurs 1983; 5: 39-44.

163 Pinchcofsky-Devin G. Why'won't this wound heal? Ostomy/ Wound Management 1989; 24: $42-51$.

164 Mulholland JH et al. Protein metabolism and bed sores. Ann Surg 1943; 118: $1015-1023$.

165 Perkash A, Brown M. Anemia in patients with traumatic spinal cord injury. J Am Paraplegia Soc 1986; 9: 10-15.

166 Bildsten C, Lamid S. Nutritional management of a patient with brain damage and spinal cord injury. Arch Phys Med Rehabil 1983; 64: $382-383$.

167 Jhangiani S et al. Nutritional aspects of decubitus ulcers. Am J Clin Nutr 1985; 41: 848

168 Breslow R. Nutritional status and dietary intake of patients with pressure ulcers: review of research literature 1943 to 1989. Decubitus 1991; 4: 16-21.

169 Bernstein LH, Shaw-Stiffel TA, Schorow M, Brouillette R. Financial implications of malnutrition. Clin Lab Med 1993; 13: 491- 507 .

170 Holmes R et al. Combating pressure sores-nutritionally. Amer J Nurs 1987; 87: 1301 - 1303 .

171 Hanan K, Scheele L. Albumin vs. weight as a predictor of nutritional status and pressure ulcer development. Ostomy/ Wound Management 1991; 33: 22 - 27.

172 Marchette L, Arnell I, Redick E. Skin ulcers of elderly surgical patients in critical care units. Dimen Crit Care Nurs 1991; 10: $321-329$.

173 Bobel LM. Nutritional implications in the patient with pressure sores. Nurs Clin N Amer 1987; 22: 379-390.

174 Wysocki AB. Surgical wound healing. AORN Journal 1989; 49: $502-518$.

175 Mecray PM, Barden RP, Ravdin IS. Nutritional edema: Its effect on the gastric emptying time before and after gastric operations. Surgery 1937; 1: 53-64.
176 Waltman NL et al. Nutritional status, pressure sores, and mortality in elderly patients with cancer. Oncol Nurs Forum 1991; 18: $867-873$.

177 Myers SA et al. Consistent wound care and nutritional support in treatment. Decubitus 1990; 3: 16-28.

178 Perkash A, Brown M. Anaemia in patients with traumatic spinal cord injury. Paraplegia 1982; 20: $235-236$

179 Artigue RS, Hyman WA. The effect of myoglobin on the oxygen concentration in skeletal muscle subjected to ischemia. Ann Biomed Eng 1976; 4: 128 - 137.

180 Hirsch GH, Menard MR, Anton HA. Anemia after traumatic spinal cord injury. Arch Phys Med Rehab 1991; 72: 195-201.

181 Burr RG, Clift-Peace L, Nuseibeh I. Haemoglobin and albumin as predictors of length of stay of spinal injured patients in a rehabilitation centre. Paraplegia 1993; 31: 473-478.

182 Corti MC, Guralnik JM, Salive ME, Sorkin JD. Serum albumin level and physical disability as predictors of mortality in older persons. JAMA 1994; 272: 1036- 1042.

183 Shea JD. Pressure sores-classification and management. Clin Ortho 1975; 112: 89 - 100

184 Welch PK, Dowson M, Endres JM. The effect of nutrient supplements on high risk long term care residents receiving pureed diets. $J$ Nutr Elder 1991; 10: $49-62$.

185 Breslow RA et al. The importance of dietary protein in healing pressure ulcers. J Am Geriat Soc 1993; 41: 357-362.

186 Malassigne $\mathrm{P}$ et al. Toward the design of a new bowel care chair for the spinal cord injured: a pilot study. SCI Nurs 1993; 10: $84-90$.

187 National Institute on disability and rehabilitation research. NIDRR National Consensus Conference, Washington, DC: US Department of Education, 1989.

188 Ferguson-Pell MW, Wilkie IC, Reswick JB, Barbenel JC. Pressure sores prevention for the wheelchair bound spinal injury patient. Paraplegia $1980 ; 18: 42-51$.

189 Sparks SM. Clinical validation of pressure ulcer risk factors. Ostomy/Wound Manage 1993; 39: 40-51.

190 Allman RM et al. Pressure ulcer risk factors among hospitalized patients with activity limitations. J Amer Med Assoc 1995; 273: $865-870$. 